\title{
Spectroscopic Characterization of Electrodeposited Poly(o-toluidine) Thin Films and Electrical Properties of ITO/Poly(o-toluidine)/Aluminum Schottky Diodes
}

\author{
A. Elmansouri, ${ }^{1}$ A. Outzourhit, ${ }^{1}$ A. Oueriagli, ${ }^{1}$ A. Lachkar, ${ }^{2}$ N. Hadik, ${ }^{1}$ M. E. Achour, ${ }^{3}$ A. Abouelaoualim, ${ }^{1}$ \\ K. Berrada, ${ }^{4}$ and E. L. Ameziane ${ }^{1}$ \\ ${ }^{1}$ LPSCM, Département de Physique, Faculté des Sciences Semlalia, Université Cadi Ayyad, Marrakech 40000, Morocco \\ ${ }^{2}$ LSM, Département de Chimie, Faculté des Sciences Semlalia, Université Cadi Ayyad, Marrakech 40000, Morocco \\ ${ }^{3}$ LAMO, Département de Physique, Faculté des Sciences, Université Cadi Ayyad, Kenitra 14000, Morocco \\ ${ }^{4}$ SIAM, Département de Physique, Faculté des Sciences Semlalia, Université Cadi Ayyad, Marrakech 40000, Morocco
}

Received 29 July 2007; Accepted 8 October 2007

Recommended by Yalin Lu

\begin{abstract}
Poly(o-toluidine) (POT) thin films were synthesized by electrochemical polymerization under cyclic voltammetric conditions from o-toluidine monomer in an aqueous solution of $\mathrm{HCl}$ as a supporting electrolyte. The electrosynthesized films were characterized by UV-Visible, FT-Raman, and FTIR spectroscopies. The optical transmissions of the as-deposited films were measured in the $400-$ $900 \mathrm{~nm}$ wavelength range. These measurements showed that the optical band gap of the polymer films is in the order of $2.52 \mathrm{eV}$. The FT-Raman and FTIR measurements showed that the POT film is composed of imine and amine units. ITO/POT/Al devices were fabricated by thermal evaporation of aluminum circular contacts on films deposited on ITO-coated glass. The nonlinear current-voltage characteristics of these devices indicate a rectifying behavior. The diode parameters were calculated from I-V characteristics using the modified Shockley equation. The measured C-V and C-F characteristics are presented.
\end{abstract}

Copyright (c) 2007 A. Elmansouri et al. This is an open access article distributed under the Creative Commons Attribution License, which permits unrestricted use, distribution, and reproduction in any medium, provided the original work is properly cited.

\section{INTRODUCTION}

$\pi$-conjugated polymers have received a great deal of attention due to their potential technological applications. These materials have been considered as active electrode materials in energy storage [1], optoelectronic devices [2], and display devices [3]. These polymers include polypyrrole [4], polyaniline [5], polythiophene [6], and other conjugated polymers [7].

In particular, polyaniline (PANI) has attracted attention due to its interesting electrochemical and optical properties, moderate conductivity, as well as environmental stability. This polymer may be obtained by electrochemical and chemical oxidative polymerization of aniline in aqueous solutions.

Poly(o-toluidine) (POT) is a PANI derivative which contains the $-\mathrm{CH}_{3}$ group in the ortho position of the aromatic ring of the aniline monomer. Among the ring-substituted PANI derivatives, POT has been probably the most widely studied one. Indeed, Ram and Borole $[8,9]$ as well as other authors [10] have studied the electropolymerization of otoluidine using various electrolytes with different concentrations. These works revealed that POTs have interesting electro-optical properties and can be used as electrochromic and electronic devices.

On the other hand, a metal/polymer junction with electrochemically or chemically synthesized polyaniline has been used to make Schottky barrier-type diodes. R. A. Nafdey and other authors [11-14] studied Schottky barriertype devices of doped PANI with various dopants $(\mathrm{HCl}$, $\mathrm{I}_{2}, \mathrm{FeCl}_{3}$, formic acid, etc.). They estimated various electronic parameters such as the ideality factor, the barrier height, the work function, the Richardson constant, and the saturation current density from current-voltage (I-V) and capacitance-voltage $(\mathrm{C}-\mathrm{V})$ measurements that were carried out on metal/polyaniline junctions. However, only a few studies were performed on Schottky diodes using a substituted polyaniline derivative. Indeed, Huang et al. [15] and Carrara et al. [16] have reported I-V characteristics of Schottky diodes using a methoxy-substituted polyaniline 
(o-anisidine and 2,5-dimethoxyaniline monomers). In this regard, no studies have been performed on metal/POT junctions.

The aim of this work is to fabricate POT thin films by cyclic voltammetry in aqueous electrolyte and Schottky diode based on these POT films. The junction properties of POT/Al devices were studied by following the I-V and C-V characteristics and were compared with those of other polymers such as polypyrrole, polythiophene, PANI, and some of its derivatives.

\section{EXPERIMENTAL PROCEDURE}

\subsection{Electrochemical deposition of POT}

POT films were synthesized electrochemically on indium tin oxide (ITO) coated glass electrode under cyclic voltammetric conditions in a simple one-compartment glass cell. Cyclic voltammetric studies were performed with computercontrolled potentiostat/galvanostat (EG\&G model 273A).

A three-electrode cell assembly was used during the electrochemical polymerization employing ITO-coated glass substrate as working electrode, a platinum foil as a counter electrode, and a saturated calomel electrode (SCE) as a reference electrode. All the potentials are referred to the SCE. The reference electrode was kept in close proximity of the working electrode $(d=18 \mathrm{~mm})$ in order to minimize the electrolytic ohmic drop.

The ITO-coated glass substrates were ultrasound cleaned in acetone and distilled water several times and were airdried. The o-toluidine monomer is distilled before use.

Poly(o-toluidine) films were synthesized in an aqueous solution containing $241.9 \mathrm{~mL}$ of $\mathrm{HCl}(2 \mathrm{M})$ and $8.1 \mathrm{~mL}$ of distilled o-toluidine $(0.3 \mathrm{M})$. The potentials were scanned between -0.15 and $0.85 \mathrm{~V} / \mathrm{SCE}$ with a scan rate of $20 \mathrm{mV} / \mathrm{s}$. The 12 th cycle is stopped at $0.45 \mathrm{~V} / \mathrm{SCE}$ in the reverse scan. To initiate the reaction of polymerization, an alternative approach was also applied; namely, before the first cycle, a fixed potential of $0.8 \mathrm{~V} / \mathrm{SCE}$ is applied during three minutes.

After the electropolymerization, the thin film is washed with the distilled water in order to remove the low-molecular soluble products and is dried in ambient air. The thickness of the obtained POT films is found to be $0.15 \mu \mathrm{m}$.

The microstructure of the obtained films was investigated by a scanning electron microscope (JEOL JSM 5500). A scanning electron micrograph of POT thin films is shown in Figure 1. The films were uniform and the examination of their surface morphology did not reveal any presence of pinholes or porosity.

\subsection{UV-visible spectroscopy}

The optical transmission (absorption) of the electrodeposited POT films was recorded using Shimadzu-3101 PC double-beam spectrophotometer in the wavelength range of 400-900 nm. The transmission spectrum of the POT/ITOcoated glass sample was normalized with that of the ITO glass.

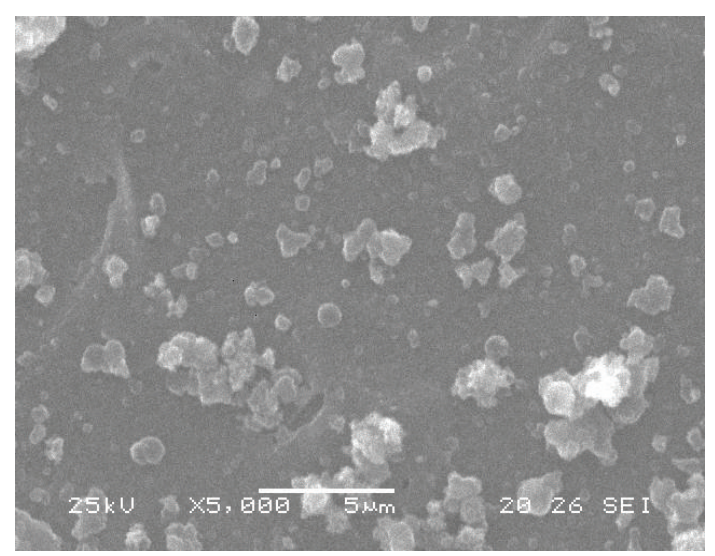

FIGURE 1: SEM micrograph of an electrodeposited POT thin film on ITO-coated glass.

\subsection{FT-raman and FTIR spectroscopies}

The FT-Raman spectra were recorded using a Bruker RFS 100 FT-Raman instrument in the spectral range of 300$1800 \mathrm{~cm}^{-1}$. The IR-excitation $(1064 \mathrm{~nm})$ line of $100 \mathrm{~mW} \mathrm{Nd}$ Yag laser was used.

FTIR measurements of POT film were obtained using an FTIR Bruker VERTEX70 instrument in the attenuated total reflection mode and in the spectral range of $500-2000 \mathrm{~cm}^{-1}$. The resolution of the IR measurements was equal to $4 \mathrm{~cm}^{-1}$.

\subsection{Junction fabrication and electrical measurements}

Schottky barrier-type devices were fabricated using the POT films deposited on ITO-coated glass substrates which provided the back contact. The front contact was made by $2 \mathrm{~mm}$ diameter circular aluminum dots. The aluminum was deposited by thermal evaporation of $99.99 \%$ purity aluminum shots for two minutes at base pressure of $1.5 \times 10^{-5} \mathrm{mbar}$.

The electrical measurements were performed on ITO/POT/Al devices at room temperature. The impedance measurements (capacitance-voltage, capacitance-frequency) were carried out using a Keithley 3330 LCZ impedance meter. The current-voltage characteristics, on other hand, were measured using a Keithley 410 programmable picoamperemeter, a $610 \mathrm{C}$ programmable microvoltmeter. All the instruments are controlled by computer via a GPIB card.

\section{RESULTS AND DISCUSSION}

\subsection{Electrochemical characteristics of poly(o-toluidine)}

Figure 2 shows the cyclic voltammograms (CVs) recorded during the electrodeposition of POT film on ITO-coated glass electrodes. These cycles clearly reveal the formation of electroactive conducting polymer films.

The regular increase of the current from one cycle to another indicates that the monomer dissolved in the solution is oxidized at the surface of the electrode and the conductivity 


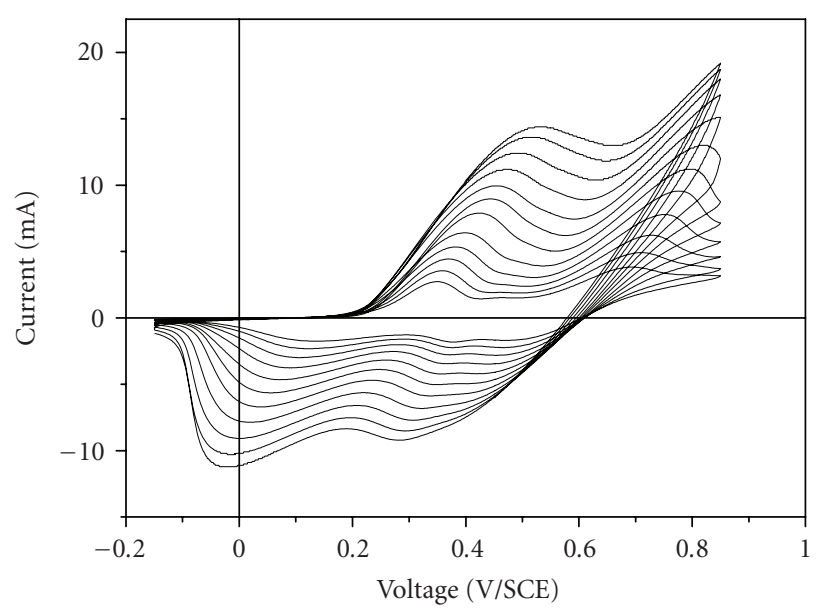

FIgURE 2: Cyclic voltammogram recorded during the synthesis of POT films in an aqueous solution of $\mathrm{HCl}$.

of deposits is sufficient to assure the propagation of the polymerization process.

The cyclic voltammograms of the POT electrode present a first anodic (oxidization) peak at $0.42 \mathrm{~V} / \mathrm{SCE}$ and a second oxidization peak at $0.79 \mathrm{~V} / \mathrm{SCE}$ (for the 6th cycle). It should be noted that the oxidization potential of O-toluidine monomer depends on the size and nature of the anion present in the solution [17]. In the reverse scan, as the potential is decreased from 0.85 to $-0.15 \mathrm{~V}$ versus SCE, the cathodic current is increased indicating that the POT film thickness is reduced. In addition, two reduction couples are present in the CVs at -0.02 and $0.28 \mathrm{~V} / \mathrm{SCE}$ (for the 6th cycle).

The two peaks observed at 0.42 and $0.79 \mathrm{~V} / \mathrm{SCE}$ are assigned to the oxidization of POT deposited on the working electrode, and most likely to the conversion of amine units to radical cations [18]. They, respectively, correspond to the formation of radical cations (polaron formation in emeraldine (E) form) from the leucoemeraldine form, and their oxidization to dications (bipolaron formation in pernigraniline form). Figure 3 represents the conversion of the fully reduced leucoemeraldine (LE) form of POT into its fully oxidized pernigraniline (PN) form [19].

While passing from one cycle to the other, the oxidization peaks shift towards higher potentials (from 0.35 to $0.53 \mathrm{~V} / \mathrm{SCE}$ for the first peak and from 0.69 to $0.85 \mathrm{~V} / \mathrm{SCE}$ for the second peak). This can be explained by the fact that the oxidation potential of the polymer increases with the length of the polymeric chain.

\subsection{Optical properties of the electrodeposited POT films}

A typical absorption spectrum of a POT film electrodeposited on IT-coated glass by cyclic voltammetry is presented in Figure 4. It shows two absorption bands centered at $436 \mathrm{~nm}$ and $580 \mathrm{~nm}$. The first absorption band is usually attributed to $\pi-\pi^{*}$ electronic transitions of the benzene rings on the basis of studies performed on polyanilines and the-

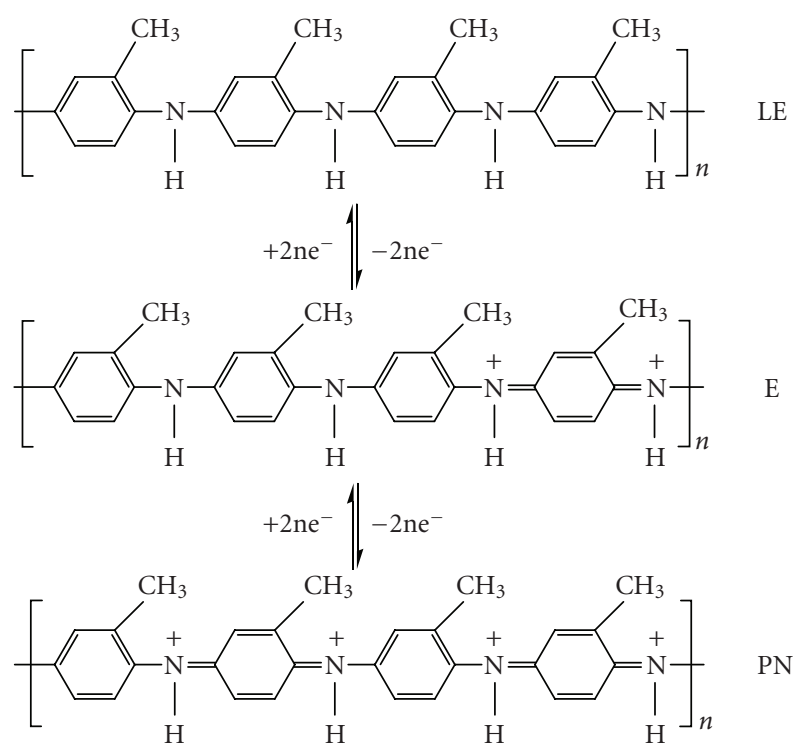

FIgure 3: Reaction schemes for the electrochemical process of POT film in acidic solutions.

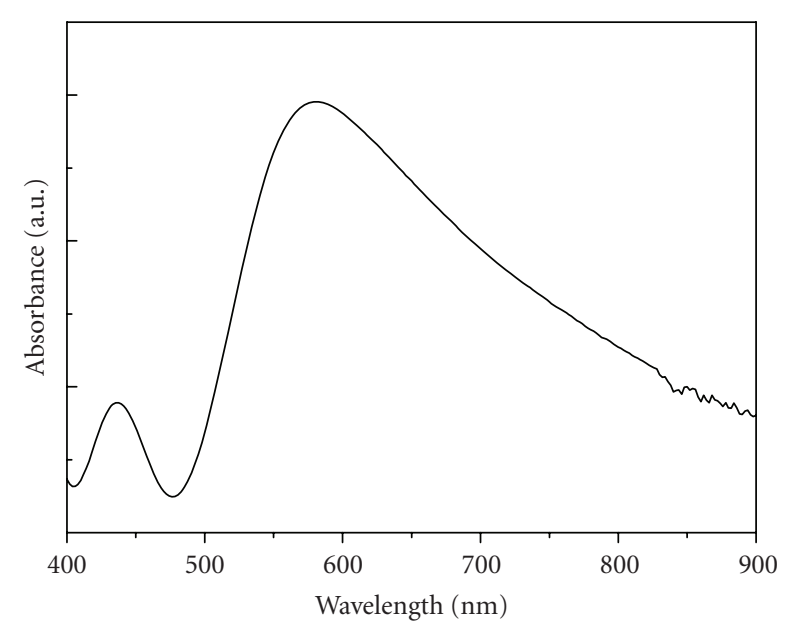

FIGURE 4: UV-Vis absorbance spectrum of an electrodeposited POT film.

oretical band structure calculations [10,20]. The position of this peak is related to the degree of conjugation between the adjacent phenylene rings in the polymer chain [20]. This peak showed a hypsochromic shift relative to the corresponding transition in PANI, thus revealing a reduction in the conjugation length in POT as a result of the steric effects of the $-\mathrm{CH}_{3}$ groups. The second absorption band at $580 \mathrm{~nm}$ is attributed to excitonic transitions between the HOMO orbital of the benzenoid ring and the LUMO orbital of the quinoid ring. It corresponds to the $n-\pi^{*}$ transition [20], which is attributed to the formation of pernigraniline base form of POT.

The optical band gap energy $\left(E_{g}\right)$ is obtained using the fundamental law

$$
\alpha=A\left(E_{g}-h v\right)^{n}
$$


TABLE 1: Assignments of FT Raman bands of electrodeposited POT films.

\begin{tabular}{lc}
\hline Wave number $\left(\mathrm{cm}^{-1}\right)$ & Raman assignments \\
\hline 449 & C-N stretching in SQ and Q rings \\
515 & C-C stretching in SQ and Q rings \\
575 & C-C stretching in B ring \\
727 & C-C stretching in B ring \\
812 & C-C stretching in B ring \\
1119 & C-C in methyl-substituted SQ and Q rings \\
1157 & C-H in SQ ring \\
1219 & C-N in B ring \\
1260 & C-N stretching in SQ and Q rings \\
1362 & C-N stretching (protonation) \\
1499 & C=N vibration in the polymer chain \\
1610 & C=C stretching in B ring \\
\hline
\end{tabular}

where $\alpha$ is the absorption coefficient, $(h v)$ is the photon energy, $A$ is a proportionality constant, and $n=1 / 2$ for direct transitions and $n=2$ for indirect allowed transitions. The value of $n$ for our sample is estimated from the slope of the $\log \alpha$ versus $\log h v$ plot by taking a linear fit. The value of $n$ is approximatively equal to 0.5 suggesting a direct transition. A similar value was used by Huang et al. to calculate the band gap energy for substituted polyaniline [15].

In this case, the optical band gap energy $\left(E_{g}\right)$ can be obtained by plotting $(\alpha h v)^{2}$ versus $(h v)$ and extrapolating the linear portion of $(\alpha h v)^{2}$ to zero. In our case, the allowed direct transition optical gap is found to be $2.52 \mathrm{eV}$ for the POT films. This value is lower than that found by Ram et al. [8] for POT films deposited on ITO-coated glass by cyclic voltammetry, dip-coating, and Langmuir-Blodgett techniques. This may be due to differences in the conditions of synthesis such as the nature of the electrolyte, the range of the potential applied, the thickness of the layer, the degree of polymerization of the polymer, and so forth. In comparison with the band gap energy of PANI lying between 4.1 and $4.28 \mathrm{eV}$ [21], this downshift is attributed to the presence of $-\mathrm{CH}_{3}$ groups in POT and its doping state. In our case, the POT films are neutralized by rinsing them with distilled water.

\subsection{FT-Raman and FT-IR spectra of electrodeposited POT films}

The FT-Raman spectra of electrodeposited POT films by cyclic voltammetry on ITO-coated glass are presented in Figure 5. The assignments of the Raman bands are grouped in Table 1.

The intense bands in the Raman spectra are situated at 1362 and $1610 \mathrm{~cm}^{-1}$. The first band is a characteristic of the $\mathrm{C}-\mathrm{N}$ stretching mode. On the basis of the studies performed on PANI [22], this band is a characteristic of the doped form of PANI; it can be due to the doping action of the distilled water and the atmosphere gases on the POT film. The second band at $1610 \mathrm{~cm}^{-1}$ is assigned to the C-C stretching mode in the benzenoid (B) rings.

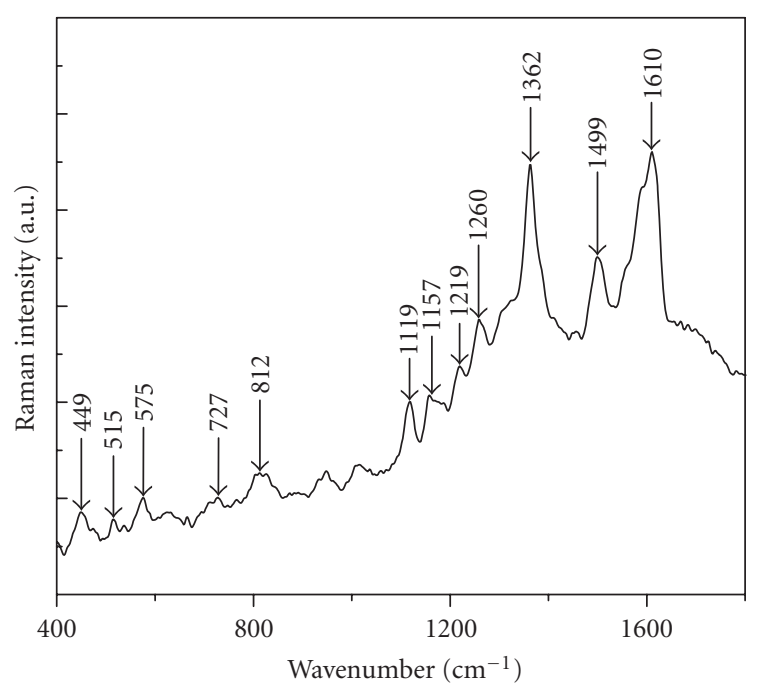

FIGURE 5: FT-Raman spectrum of an electrodeposited POT film (1064 nm excitation).

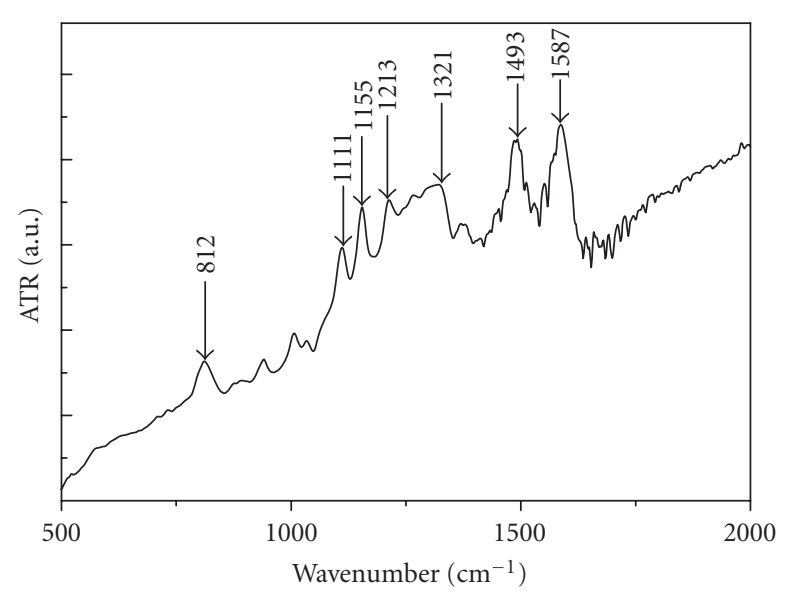

FIGURE 6: FTIR spectrum of an electrodeposited POT film.

Contrary to PANI [23], a new band appeared at $1119 \mathrm{~cm}^{-1}$ in the POT spectrum. This band is attributed to the $\mathrm{C}-\mathrm{C}$ vibration in the methyl-group substituted semiquinoid (SQ) and quinoid (Q) rings.

The presence of the characteristic bands of quinoid (Q) and benzenoid (SQ) rings shows that the electrodeposited POT by cyclic voltammetry is composed of amine and imine units.

The FTIR spectra of the electrodeposited POT film by cyclic voltammetry on ITO-coated glass substrate are presented in Figure 6. This spectrum exhibits the following main spectral features [24-26].

(i) The broadband at $1587 \mathrm{~cm}^{-1}$ can be assigned to the $\mathrm{C}-\mathrm{C}$ stretching mode combined with $\mathrm{C}=\mathrm{N}$ stretching vibrations of the quinoid rings.

(ii) The band at $1493 \mathrm{~cm}^{-1}$ is attributed to the C-C stretching modes in the benzenoid units. 


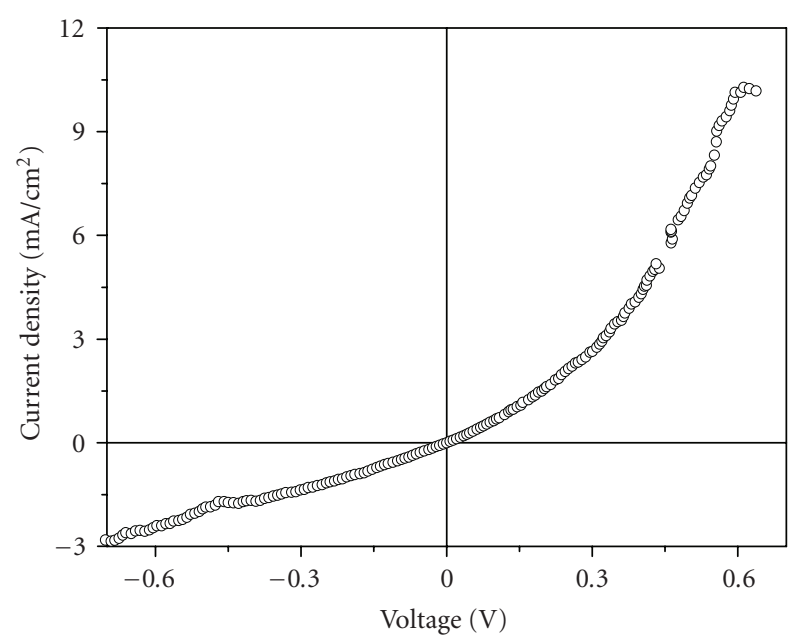

FIGURE 7: Current-voltage characteristic of ITO/POT/Al devices.

(iii) The bands at $1321 \mathrm{~cm}^{-1}$ and $1213 \mathrm{~cm}^{-1}$ are assigned to the $\mathrm{C}-\mathrm{N}$ stretching vibrations in the polymer chain.

(iv) The band at $1155 \mathrm{~cm}^{-1}$ is related to the $\mathrm{C}=\mathrm{N}$ stretching mode; this band is a characteristic of doped POT. It can be due to the doping of the POT films by the ambient gases.

(v) The band at $1111 \mathrm{~cm}^{-1}$ can be attributed to charge delocalization on the polymer backbone.

(vi) The band located at $812 \mathrm{~cm}^{-1}$ represents the paradisubstituted benzenoid rings in POT film.

In addition, the presence of quinoid and benzenoid bands ( 1587 and $1493 \mathrm{~cm}^{-1}$ ) shows that the electrodeposited POT by cyclic voltammetry is composed of imine and amine units. Therefore, the FTIR spectroscopy results are in good agreement with the FT-Raman spectroscopy results.

\subsection{Electrical properties of ITO/POT/AI device}

\subsubsection{Current-voltage characteristics}

Figure 7 shows a typical J-V characteristic of an ITO/POT/Al device at room temperature. The rectification ratio of these devices is about 4.12 at $\pm 0.6 \mathrm{~V}$. This value is higher than that obtained for poly(o-methoxyaniline) electropolymerized on ITO-coated glass [15].

With polyaniline being well known as an intrinsic p-type semiconductor, the work function of this polymer is usually reported to lie between 4.1 and $4.28 \mathrm{eV}[27,28]$. Contacts of PANI with lower work function materials such as aluminum $\left(\varphi_{\mathrm{Al}}=3.7\right.$ to $\left.4 \mathrm{eV}\right)$, as in our case, are therefore expected to be rectifying contact. Metals with work functions higher than those of PANI, such as gold $\left(\varphi_{\text {Au }}=5.1 \mathrm{eV}\right)$ and ITO $\left(\varphi_{\text {ITO }}=\right.$ $4.7 \mathrm{eV})$, are expected to be ohmic contacts.

The current transport across the polymer/metal junction is usually accounted for on the basis of thermionic emission, space charge-limited current (SCLC), or Poole-Frenkel emission [28-31]. The last two mechanisms are found not to be applicable to our diodes in the exploited voltage range, as revealed by fitting their respective laws to experimental data.

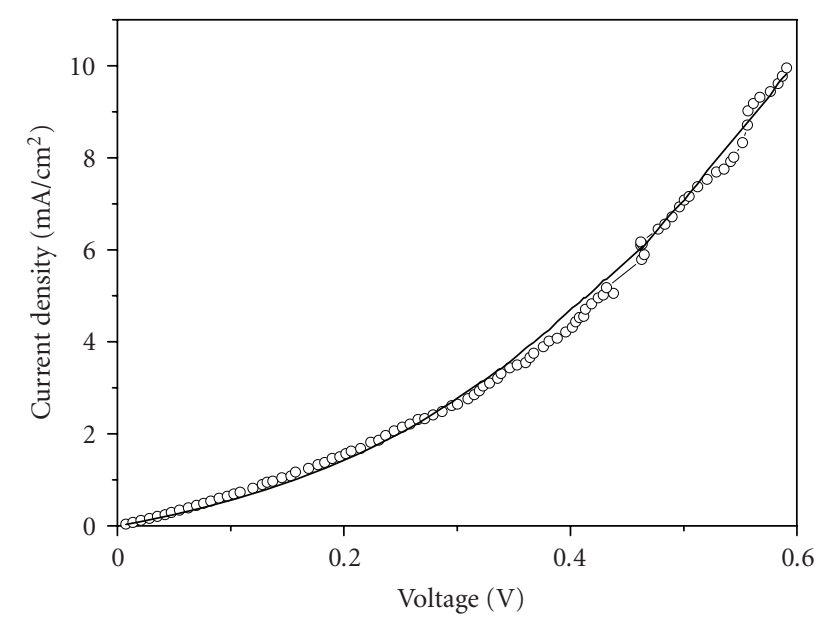

FIgURE 8: Experimental I-V characteristic of ITO/POT/Al devices ( $\circ$ ) and fits (line) using (4) in the forward bias region.

For the thermionic emission model, the J-V relationship is expressed by

$$
J=J_{0}\left[\exp \left(\frac{q V}{\eta k T}\right)-1\right] .
$$

$J_{0}$ is the saturation current, $q$ is the elementary charge (e), $V$ is the applied voltage, $k$ is the Boltzman constant, $\eta$ is the diode ideality factor, and $T$ is the absolute temperature.

The saturation current density is given by

$$
J_{0}=S A^{*} T^{2} \exp \left(-\frac{q \Phi_{B}}{k T}\right),
$$

where $S$ is the surface area of the diode (top $\mathrm{Al}$ contact), $A *$ is the Richardson constant which depends on the effective mass of the carriers (120 $\mathrm{A} \mathrm{cm}^{-2} \mathrm{~K}^{-2}$ for free carriers), and $\Phi_{B}$ is the barrier height.

A better model, taking into account the series resistance $\left(R_{s}\right)$ of the structure, was used. This model is described by the following modified Shockley equation:

$$
J=J_{0}\left[\exp \left(\frac{q\left(V-R_{s} J\right)}{\eta k T}\right)-1\right] .
$$

As shown in Figure 8, this model accounts well for the experimental data over the explored voltage range in the forward bias region. The fit (4) yielded the following diode parameters: $\eta=7.3$, saturation current density $J_{0}=8.910^{-4}$ $\left(\mathrm{A} / \mathrm{cm}^{2}\right)$, and $R_{s}=380 \Omega$.

The value of the ideality factor of ITO/POT/Al Schottky devices is higher than unity, but lower than that found for the polypyrrole/metal and polyhexylthiophene/metal Schottky diodes [30, 31]. The deviation of ideality factor from ideal value may be due to the following effects $[13,32,33]$ :

(i) recombination of electrons and holes in the depletion region,

(ii) presence of barrier inhomogeneities as well as the reactive nature of $\mathrm{Al}$ contact, 


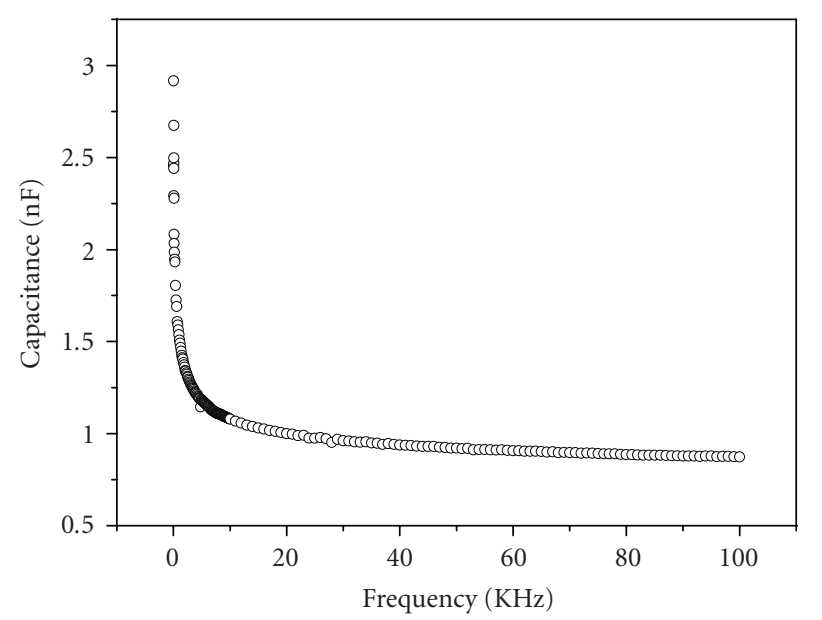

FIGURE 9: Capacitance-frequency characteristic of ITO/POT/Al structure.

(iii) possibility of presence of other conduction mechanisms such as bulk-limited currents in various voltage ranges and trap-assisted tunneling [6].

The barrier height $\Phi_{B}$ obtained from $J_{0}$ (see (3)) is equal to $0.59 \mathrm{eV}$. This value is in good agreement with those reported for a metal/polymer interface $[31,34,35]$.

\subsubsection{C-V and C-F characteristics}

Figure 9 displays the frequency dependence of the zero-bias capacitance in the frequency range of $40-100 \mathrm{KHz}$. The capacitance decreased by a factor of two when the frequency was increased to $10 \mathrm{kHz}$. This dispersion in capacitance can be explained on the basis of a distribution of localized states in the band gaps of the amorphous polymer [36]. The influence of the barrier inhomogeneities and series resistance of the diode is not ruled out as in the case of poly(3methylthiophene)-based diodes $[37,38]$.

Figure 10 shows the voltage dependence of the capacitance at $1 \mathrm{kHz}$ for applied voltages between $-0.5 \mathrm{~V}$ and $+0.5 \mathrm{~V}$. As expected, the capacitance increased slightly when the voltage was scanned from the reverse bias region to the forward bias region. This behavior further confirms the rectifying nature of the POT/Al contact. The plot $\left(\mathrm{C}^{-2}\right)$ versus $(\mathrm{V})$ is not linear, which further suggests a distribution of deep states in the forbidden band.

\section{CONCLUSION}

We have successfully deposited poly(o-toluidine) thin films on ITO-coated glass substrates by cyclic voltammetry. $\mathrm{Al} / \mathrm{POT} / \mathrm{ITO}$ devices were also fabricated. The optical band gap of the obtained POT films is found to be $2.52 \mathrm{eV}$; it is lower than that of films deposited by dip-coating and Langmuir-Blodgett techniques. The FTIR and FTRaman spectroscopies results are in good agreement with those of the UV-Vis spectroscopy. On the other hand, the $\mathrm{Al} / \mathrm{POT} / \mathrm{ITO}$ devices showed a rectifying behavior. The I-V

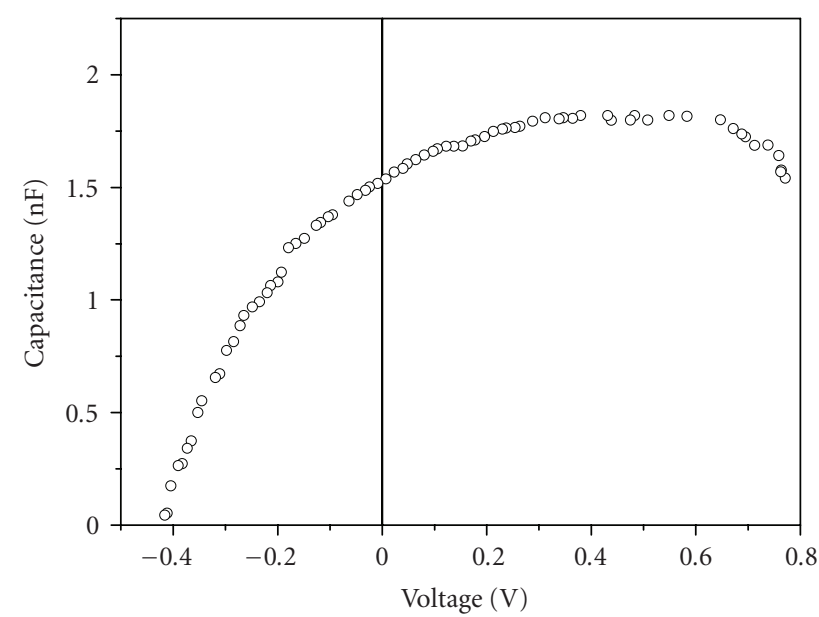

Figure 10: Capacitance-voltage characteristic of ITO/POT/Al structure.

characteristics of these devices are fitted with the modified Shockley diode equation. The large value of ideality factor suggests the presence of other transport mechanisms (bulklimited current and/or trap assisted tunneling). This is further supported by both $\mathrm{C}-\mathrm{V}$ and $\mathrm{C}-\mathrm{F}$ measurements which suggest a distribution of localized states in the band gap of the polymer.

\section{REFERENCES}

[1] A. G. Macdiarmid, S.-L. Mu, N. L. D. Somasiri, and W. Wu, "Electrochemical characteristics of "polyaniline" cathodes and anodes in aqueous electrolytes," Molecular Crystals and Liquid Crystals, vol. 121, no. 1, pp. 187-190, 1985.

[2] E. W. Paul, A. J. Ricco, and M. S. Wrighton, "Resistance of polyaniline films as a function of electrochemical potential and the fabrication of polyaniline-based microelectronic devices," Journal of Physical Chemistry, vol. 89, no. 8, pp. 14411447, 1985.

[3] A. Kitani, J. Yano, and K. Sasaki, "ECD materials for the three primary colors developed by polyanilines," Journal of Electroanalytical Chemistry, vol. 209, no. 1, pp. 227-232, 1986.

[4] J. Lei, W. Liang, C. J. Brumlik, and C. R. Martin, "New interfacial polymerization method for forming metal/conductive polymer Schottky barriers," Synthetic Metals, vol. 47, no. 3, pp. 351-359, 1992.

[5] M. Narasimhan, M. Hagler, V. Cammarata, and M. Thakur, "Junction devices based on sulfonated polyaniline," Applied Physics Letters, vol. 72, no. 9, pp. 1063-1065, 1998.

[6] S. Tagmouti, A. Outzourhit, A. Oueriagli, et al., "Electronic properties of poly(3-methylthiophene)," Solar Energy Materials and Solar Cells, vol. 71, no. 1, pp. 9-18, 2002.

[7] M. Willander, A. Assadi, and C. Svensson, "Polymer based devices their function and characterization," Synthetic Metals, vol. 57, no. 1, pp. 4099-4104, 1993.

[8] M. K. Ram, M. Joshi, R. Mehrotra, S. K. Dhawan, and S. Chandra, "Electrochemical and optical characteristics of conducting poly(o-toluidine) films," Thin Solid Films, vol. 304, no. 1-2, pp. 65-69, 1997.

[9] D. D. Borole, U. R. Kapadi, P. P. Kumbhar, and D. G. Hundiwale, "Influence of inorganic and organic supporting 
electrolytes on the electrochemical synthesis of polyaniline, poly(o-toluidine) and their copolymer thin films," Materials Letters, vol. 56, no. 5, pp. 685-691, 2002.

[10] D. Kumar, "Poly(o-toluidine) polymer as electrochromic material," European Polymer Journal, vol. 37, no. 8, pp. 17211725, 2001.

[11] R. A. Nafdey and D. S. Kelkar, "Schottky diode using $\mathrm{FeCl}_{3}$ doped polyaniline," Thin Solid Films, vol. 477, no. 1-2, pp. 9599, 2005.

[12] S. S. Pandey, S. C. K. Misra, B. D. Malhotra, and D. Chandra, "Some recent studies on metal/polyaniline Schottky devices," Journal of Applied Polymer Science, vol. 44, no. 5, pp. 911-915, 1992.

[13] M. Campos, L. O. S. Bulhões, and C. A. Lindino, "Gassensitive characteristics of metal/semiconductor polymer Schottky device," Sensors and Actuators A, vol. 87, no. 1-2, pp. 67-71, 2000.

[14] R. K. Gupta and R. A. Singh, "Fabrication and characteristics of Schottky diode based on composite organic semiconductors," Composites Science and Technology, vol. 65, no. 3-4, pp. 677-681, 2005.

[15] L.-M. Huang, T.-C. Wen, A. Gopalan, and F. Ren, "Structural influence on the electronic properties of methoxy substituted polyaniline/aluminum Schottky barrier diodes," Materials Science and Engineering B, vol. 104, no. 1-2, pp. 88-95, 2003.

[16] S. Carrara, V. Bavastrello, M. K. Ram, and C. Nicolini, "Nanometer sized polymer based Schottky junctions," Thin Solid Films, vol. 510, no. 1-2, pp. 229-234, 2006.

[17] R. Córdova, M. A. del Valle, A. Arratia, H. Gómez, and R. Schrebler, "Effect of anions on the nucleation and growth mechanism of polyaniline," Journal of Electroanalytical Chemistry, vol. 377, no. 1-2, pp. 75-83, 1994.

[18] W.-S. Huang, B. D. Humphrey, and A. G. Macdiarmid, "Polyaniline, a novel conducting polymer. Morphology and chemistry of its oxidation and reduction in aqueous electrolytes," Journal of the Chemical Society. Faraday Transactions, vol. 82, no. 8, pp. 2385-2400, 1986.

[19] D. Wei, T. Lindfors, C. Kvarnström, L. Kronberg, R. Sjöholm, and A. Ivaska, "Electrosynthesis and characterisation of poly ( $N$-methylaniline) in organic solvents," Journal of Electroanalytical Chemistry, vol. 575, no. 1, pp. 19-26, 2005.

[20] A. Pron and P. Rannou, "Processible conjugated polymers: from organic semiconductors to organic metals and superconductors," Progress in Polymer Science, vol. 27, no. 1, pp. 135190, 2002.

[21] H. Koezuka and S. Etoh, "Schottky barrier type diode with an electrochemically prepared copolymer having pyrrole and $\mathrm{N}$ methylpyrrole units," Journal of Applied Physics, vol. 54, no. 5, pp. 2511-2516, 1983.

[22] K. Berrada, S. Quillard, G. Louarn, and S. Lefrant, "Polyanilines and substituted polyanilines: a comparative study of the Raman spectra of leucoemeraldine, emeraldine and pernigraniline," Synthetic Metals, vol. 69, no. 1-3, pp. 201-204, 1995.

[23] A. Buzarovska, I. Arsova, and L. Arsov, "Electrochemical synthesis of poly(2-methyl aniline): electrochemical and spectroscopic characterization," Journal of the Serbian Chemical Society, vol. 66, no. 1, pp. 27-37, 2001.

[24] A. Gruger, A. Novak, A. Régis, and Ph. Colomban, "Infrared and Raman study of polyaniline-part II: influence of ortho substituents on hydrogen bonding and UV/Vis-near-IR electron charge transfer," Journal of Molecular Structure, vol. 328, pp. 153-167, 1994.
[25] E. M. Andrade, F. V. Molina, M. I. Florit, and D. Posadas, "IR study of the first redox couple of poly(o-toluidine). Anion involvement and potential dependence in strongly acidic solutions," Journal of Electroanalytical Chemistry, vol. 415, no. 1-2, pp. 153-159, 1996.

[26] Y. H. Kim, C. Foster, J. Chiang, and A. J. Heeger, "Photoinduced localized charged excitations in polyaniline," Synthetic Metals, vol. 26, no. 1, pp. 49-59, 1988.

[27] S.-A. Chen and Y. Fang, "Polyaniline Schottky barrier: effect of doping on rectification and photovoltaic characteristics," Synthetic Metals, vol. 60, no. 3, pp. 215-222, 1993.

[28] S. C. K. Misra and S. Chandra, "Electronic applications of semiconducting polymers," Indian Journal of Chemistry, vol. 33A, pp. 583-594, 1994.

[29] G. D. Storrier, S. B. Colbran, and D. B. Hibbert, "Chemical and electrochemical syntheses, and characterization of poly(2,5-dimethoxyaniline) (PDMA): a novel, soluble, conducting polymer," Synthetic Metals, vol. 62, no. 2, pp. 179-186, 1994.

[30] R. Gupta, S. C. K. Misra, B. D. Malhotra, N. N. Beladakere, and S. Chandra, "Metal/semiconductive polymer Schottky device," Applied Physics Letters, vol. 58, no. 1, pp. 51-52, 1991.

[31] V. Saxena and K. S. V. Santhanam, "Junction properties of Schottky diode with chemically prepared copolymer having hexylthiophene and cyclohexylthiophene units," Current Applied Physics, vol. 3, no. 2-3, pp. 227-233, 2003.

[32] V. Saxena and R. Prakash, "Effect of steric hinderance on junction properties of poly(3-alkylthiophene)s based Schottky diodes," Polymer Bulletin, vol. 45, no. 3, pp. 267-274, 2000.

[33] B. Fabre, G. P. Lopinski, and D. D. M. Wayner, "Photoelectrochemical generation of electronically conducting polymerbased hybrid junctions on modified Si(111) surfaces," Journal of Physical Chemistry B, vol. 107, no. 51, pp. 14326-14335, 2003.

[34] L.-M. Huang, T.-C. Wen, and A. Gopalan, "Electronic and junction properties of poly(2,5-dimethoxyaniline)polyethylene oxide blend/metal Schottky diodes," Thin Solid Films, vol. 473, no. 2, pp. 300-307, 2005.

[35] S.-F. Chung, T.-C. Wen, and A. Gopalan, "Influence of dopant size on the junction properties of polyaniline," Materials Science and Engineering B, vol. 116, no. 2, pp. 125-130, 2005.

[36] P. Viktorovitch and D. Jousse, "Determination of the electronic density of states in hydrogenated amorphous silicon (a-SiH) from Schottky diode capacitance-voltage and conductance-voltage measurements," Journal of NonCrystalline Solids, vol. 35-36, part 1, pp. 569-574, 1980.

[37] S. Tagmouti, A. Oueriagli, A. Outzourhit, et al., "Electrical and structural properties of refractory metal Mo/poly(3methylthiophene) Schottky barrier diodes," Synthetic Metals, vol. 87, no. 2, pp. 109-113, 1997.

[38] S. Tagmouti, A. Outzourhit, A. Oueriagli, et al., "Electrical characteristics of W/P3MT/Pt diodes," Thin Solid Films, vol. 379, no. 1-2, pp. 272-278, 2000. 

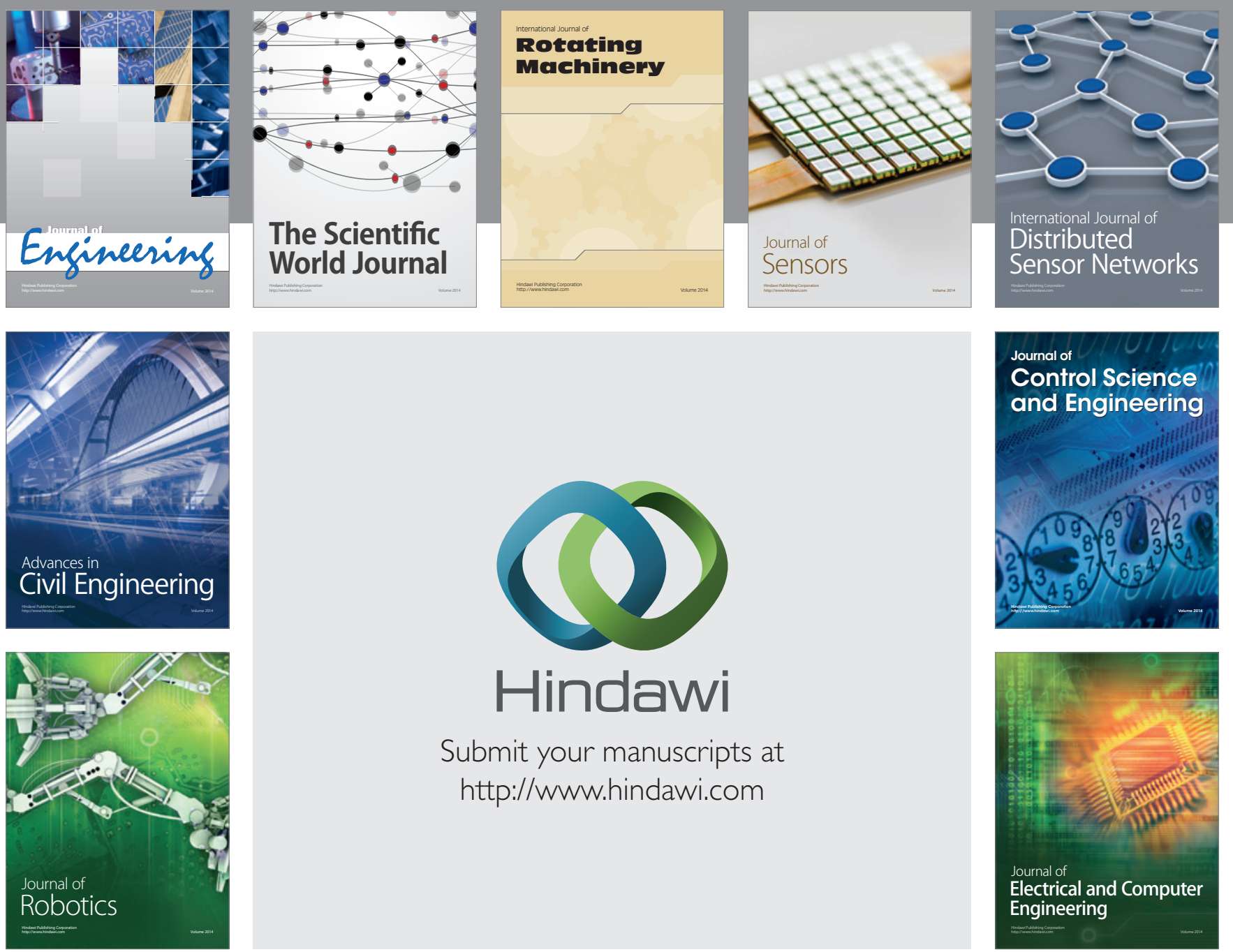

Submit your manuscripts at

http://www.hindawi.com
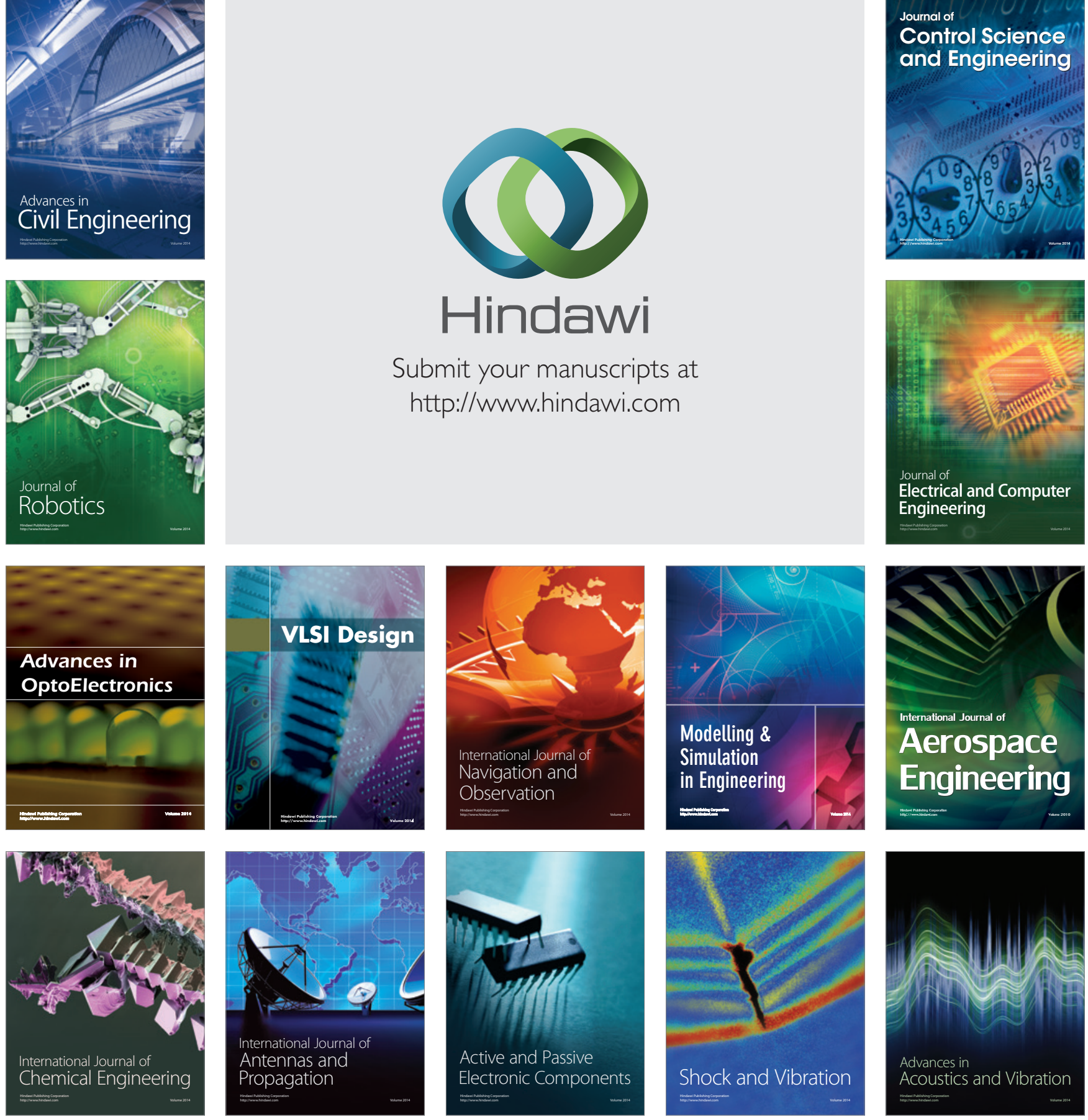